\title{
PRIMORDIAL METHODS OF ANTENATAL AND DELIVERY SERVICES ON THE PROWL IN NORTH- CENTRAL NIGERIA
}

Audu O. ${ }^{I^{*}}$, Ojabo C.O ${ }^{2}$, Ojabo A.O ${ }^{3}$, Omole V.N ${ }^{4}$, Ogbeyi G.O ${ }^{1}$, Maanongun M.T. ${ }^{3}$

Department of Epidemiology and Community Health ${ }^{1}$, Department of Ophthalmology ${ }^{2}$, Department of Obstetrics and Gynaecology ${ }^{3}$, College of Health Sciences, Benue State University, Makurdi, Nigeria and Department of Community Medicine, College of Medicine, Kaduna State University, Kaduna Nigeria ${ }^{4}$.

*Corresponding Author: Audu, Onyemocho, Department of Epidemiology and Community Health, College of Health Sciences, Benue State University, Makurdi, Nigeria. E-mail: audeeony@yahoo.com

Received date: April $03^{\text {rd }} 2018$, Accepted date: June $01^{\text {st }}$ 2018. Published date: June $30^{\text {th }} 2018$.

\begin{abstract}
The Nigeria national reproductive health policy that was put in place to control maternal mortality is yet to achieve its desired effects as it is been hampered by the activities of traditional birth attendants in most communities. This study assessed the correlates of patronage of traditional birth attendants among women of reproductive age group in three rural communities of Apa local Government area of Benue State, Nigeria. A community-based cross sectional study design was employed to study 456 women in the settlements via a multistage sampling technique. Structured interviewer administered questionnaire was used for data collection. Multiple logistic regression analysis was used to assess the independent variables that had significant chi-square at $p<0.05$. The findings revealed that patronage of traditional birth attendants amongst the respondents was $172(37.7 \%)$. The prevalent reasons for the patronage by respondents were the affordable cost of treatment $135(78.5 \%)$, cultural acceptability $80(46.5 \%)$, negative attitude of health workers $58(33.8 \%)$, proximity 51(29.7\%), and compassionate care of the traditional birth attendants 15(8.7\%), Husband's decisions 8(4.7\%) and TBAs not embarking on industrial strike 3(1.7\%). About 164(95.3\%) of those that patronize traditional birth attendants were satisfied with the services rendered. However, 33(19.2\%) admitted to have experienced complications during delivery. Education and the marital status of respondents had the highest impact $(\mathrm{Beta}=$ 3.114 and 2.486 respectively) on traditional birth attendants patronage. A more aggressive approach in advocacy and awareness campaign is therefore needed to promote the utilization of health facilities that are within the provision of the reproductive policy of the country.
\end{abstract}

Keywords: Nigeria, Primordial, delivery, Prowl, Utilization.

\section{Introduction}

Nigeria has a reproductive health policy that provides a roadmap aimed at reducing pregnancy-related morbidity and mortality over the years. In the policy, doctors, nurses, midwives and Community Health Extension Workers (CHEWs) who are trained on modified lifesaving skills through the subsidy reinvestment and empowerment programme as well as the Midwives service scheme are expected to attend to pregnant women during antenatal, delivery and post natal periods for successful pregnancies and outcomes $^{1-3}$ The services of Traditional Birth Attendants (TBAs) whose practice is as old as medicine itself are not supported in this policy. ${ }^{4}$ However, because Nigeria operates a health system where public, private and tradomedical health providers operate at will, the TBAs still have a visible role to play in health care delivery. ${ }^{5}$ Therefore, a significant proportion of antenatal care and deliveries still occurs at home under the supervision of the TBAs. In addition to pregnancy related services, some TBAs also provide some forms of social support to women in the communities, thereby earning their trust as against the skilled health professionals. ${ }^{6}$ 
National estimate shows that less than $66 \%$ of pregnant women in Benue State where our study was carried out, attend Antenatal Care (ANC) at least once, and about $64 \%$ of the annual births occur outside the health facilities. ${ }^{7}$ The high utilization of the services of skilled birth attendants did not only lead to increased maternal mortality, but as well affected the Prevention of Mother to Child Transmission (PMTCT) of HIV entry points and the PMTCT scale-up. These in turn have contributed to miss opportunities for provision of Anti-Retroviral drugs (ARVs) to Human Immunodeficiency Virus (HIV) sero-positive mothers and their babies. ${ }^{8}$ The overall effect is seen in the increased risk of maternal and infant mortality which has led to Nigeria still accounting for $10 \%$ of the global maternal mortality with 814 deaths per 100,000 live births and contributing to the largest number of deaths in Africa. ${ }^{6}$ Benue State Planning Commission Report of 2016 shows that the state has 1408 health facilities distributed in 23 LGAs, with inequity in distribution and functionality of the facilities. Certain services are not available to a large percentage of the population. ${ }^{9}$ Empirical studies on the utilization of TBAs by women in the study area was scanty, therefore, this study examined the correlates of utilization of TBAs in Oiji Ward, a rural communities in North Central Nigeria.

\section{Materials and Methods}

\section{Study area and period:}

The study was conducted in three communities of Apa Local Government Area (LGA) of Benue State between March, $13^{\text {th }}$ and April, $15^{\text {th }}$ 2017. Apa is one of the twenty-three LGAs in Benue State, North Central Nigeria. In 2017, the LGA has an estimated population of 133,945 (based on 2006 census), spreading across 84 villages (settlements) divided into 11 political districts/wards. For equity in the allocation of political appointments, the citizens divided the LGA into three zones (A B and C). The LGA shares boundary with Agatu, Otukpo, and GwerWest LGAs of Benue State to its north, south, and east, respectively, while to its west, it is bordered by Ankpa and Omala LGAs of Kogi State. The major occupation of the people is farming. The people of the LGA predominantly speak a dialect of Idoma language. The health policy of the LGA is based on Nigerian national health policy, put in place since 1986, which is based on the concept and practice of Primary Health Care (PHC). There are 50 health facilities in the LGA, 49(98.0\%) are public while $1(2.0 \%)$ is private. Of the total public health facilities, there is one comprehensive health care located at the LGA headquarters (Ugbokpo) which serves as a referral health centre for the people of the LGA and $48(98.0 \%)$ primary health facilities distributed across the 11 wards. Other health care providers include informal private health providers, patent medicine vendors, traditional healers, and faith healers. The overall health facility coverage of the LGA is 1 per 2,679 populations. $^{9}$

\section{Study design}

A community-based cross sectional study design was used for the study.

\section{Study population}

The study population was all women of reproductive age group living in Apa LGA. Those who had delivered at least a child in the last one year prior to the survey were included in the study.

\section{Sample size determination}

The minimum sample size of 383.5 was arrived at using the formula $n=Z^{2} p(1-p) d^{2,10}$ with assumption of $48.4 \%$ of deliveries attended by a unskilled health providers in Nigeria ${ }^{11}$, and $5 \%$ tolerable margin of error at $95 \%$ confidence interval. Considering attrition rate of $15 \%$, the calculated sample size was adjusted to 451. The sample size was rounded up to 456 for convenience.

\section{Sampling technique}

Multistage sampling technique was used for the study. In the first stage, all the political zones of the LGA were selected by simple random technique. In the second stage, one village from each of the political zones was selected, by convenience. What informed the selection of the villages was their estimated population and presence of PHC. The selected villages are more populated as compared to other villages in their respective zones and there are functional PHC in each of them. These villages include, Oiji from Zone C, Iga-okpaya from Zone B and Ikobi from Zone A. Stage three was the selection of actual respondents in the selected Villages. Mapping of the selected villages was done and the list of household was used as the sampling frame. A household is defined as people eating from a common pot. A compound may include many households. To ensure that the sample is spread across the settlements, once a household is selected 
three households next to the surveyed one were excluded. Where there was more than one eligible woman in a household only one was selected by simple random sampling using table of random numbers. A maximum of 152 women were selected per village.

\section{Data collection}

A structured interviewer administered questionnaire was administered to all eligible women by trained interviewers that were conversant with the local language, Idoma. The research assistants were resident doctors of the department of epidemiology and community medicine, Benue state university teaching hospital, Makurdi, Nigeria. They had a day training on the research protocol, conducted by the principal researcher before the commencement of the data collection. The questionnaires sought information on biographic profile, perception of services render by TBAs, utilization of TBAs for antenatal care/ deliveries, reasons for utilization and maternal complications experienced as a result of TBAs patronage.

\section{Data analysis}

Data was analysed using the Statistical Package for Social Sciences (SPSS) version 20.0, International Business Machines Corporation (IBM), New York, USA. Data was presented as tables. Chi-square $\left(\chi^{2}\right)$ test was used for test of association between the independent variables and the main outcome of the study, with statistical significance set at p-value of 0.05. Linear relationship between the

sociodemographic variables and the utilization of TBA by the respondents was further performed for selected independent variables that have significant chi-square, using multiple logistic regression models by controlling for possible confounders.

\section{Ethical issues}

Ethical approval for the study was obtained from the ethical committee of Benue University Hospital Makurdi, before the study was conducted. An informed written consent was also obtained from the Village heads. Verbal consent was also obtained from respondents agreeing that respondent's confidentiality must be maintained and the research was voluntary.

\section{Results}

Sociodemographic characteristics of the respondents The mean age $( \pm$ SD) of the respondents was 33 years $( \pm 3.27)$, majority were married $317(69.6 \%)$ and Christians $367(80.5 \%)$. More than one-third 201(44.1\%) of them had tertiary education, slightly below two-third 294(64.5\%) had between 3-4 children, with mean parity $( \pm \mathrm{SD})$ of $3( \pm 2.1)$ years (Table 1).

\section{Respondents' knowledge of services rendered by TBAs} The services of TBAs most commonly known by the respondents were antenatal care $(91.2 \% ; \mathrm{n}=416)$ \& deliveries $(82.2 \%$; $n=375)$, with the least known been surgeries $(0.7 \% ; n=3)$.

(Fig. 1)

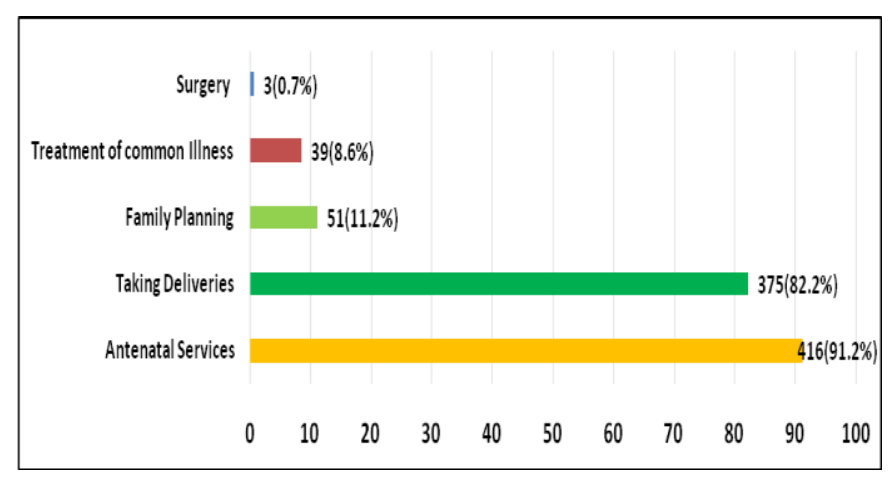

Figure 1: Respondents knowledge of services rendered by TBAs

Patronage and reasons for the preference of TBA Overall, 172(37.7\%) respondents patronise TBAs. The main reason is affordable cost $(78.5 \%$; $n=135)$, followed by TBA services being culturally acceptable $(46.5 \% ; n=80)$. The reason that TBAs never embarked on an industrial strike action (as seen in public health facilities) constitutes the least $(1.7 \% ; n=3)$.

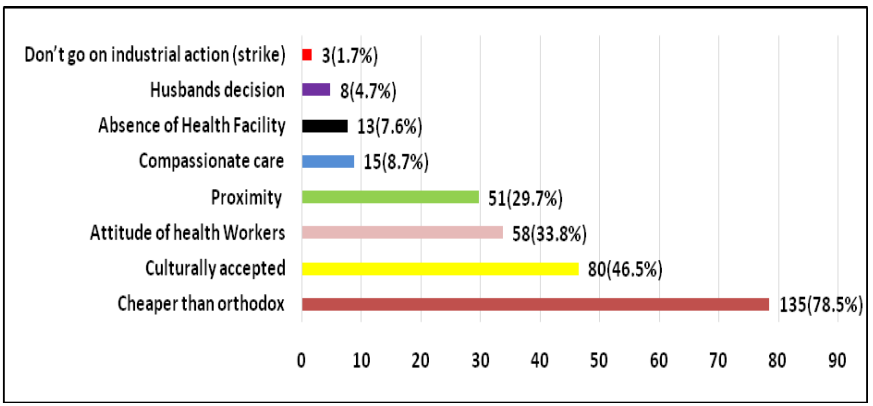

Figure 2: Reasons for TBAs Services Patronage 
Table 1: Sociodemographic characteristics of Respondents $(n=456)$

\begin{tabular}{|c|c|c|}
\hline Socio-Characteristics & Frequency & Percent \\
\hline \multicolumn{3}{|l|}{ Age group } \\
\hline$\leq 20$ & 8 & 1.8 \\
\hline $21-25$ & 38 & 8.3 \\
\hline $26-30$ & 99 & 21.7 \\
\hline $31-35$ & 95 & 20.8 \\
\hline $36-40$ & 92 & 20.2 \\
\hline $41-45$ & 75 & 16.4 \\
\hline$\geq 46$ & 49 & 10.7 \\
\hline \multicolumn{3}{|l|}{ Marital status } \\
\hline Married & 317 & 69.6 \\
\hline Divorced & 65 & 14.2 \\
\hline Single & 47 & 10.2 \\
\hline Widowed & 27 & 6.0 \\
\hline \multicolumn{3}{|l|}{ Religion } \\
\hline Christian & 367 & 80.5 \\
\hline Islam & 78 & 17.1 \\
\hline Others & 11 & 2.4 \\
\hline \multicolumn{3}{|l|}{ Education status } \\
\hline No formal education & 30 & 6.5 \\
\hline Quranic & 35 & 7.7 \\
\hline Primary & 54 & 11.9 \\
\hline Secondary & 136 & 29.8 \\
\hline Tertiary & 201 & 44.1 \\
\hline \multicolumn{3}{|l|}{ Parity } \\
\hline $1-2$ & 82 & 18.0 \\
\hline $3-4$ & 294 & 64.5 \\
\hline$\geq 5$ & 80 & 17.5 \\
\hline Mean $=3( \pm 2.1)$ & & \\
\hline
\end{tabular}

Relationship between biographic profile of respondents and patronage of TBA

The older respondents constituted the majority of those that patronize TBAs. Patronage among the married was higher while single was the least. Patronage was highest amongst the Christians; increasing parity was associated with higher patronage. Ironically, those with higher educational qualification constituted the majority of those that patronize TBA in our study. The relationship between age, marital status, religion \& parity and patronage of TBA was statistically significant $(\mathrm{p}<0.05)$ (Table 2$)$

Table 2: Patronage of TBAs and biographic profile of respondents

\begin{tabular}{|c|c|c|c|c|}
\hline \multirow[t]{2}{*}{ Socio-characteristics } & \multicolumn{2}{|r|}{ TBA patronage } & \multicolumn{2}{|r|}{ Statistical values } \\
\hline & Total & Yes (172) & NO (284) & \\
\hline Age (years) & & Frequency $(\%)$ & Frequency $(\%)$ & \\
\hline$\leq 20$ & 8 & $3(1.7)$ & $5(1.8)$ & $X^{2}=29.58$ \\
\hline $21-25$ & 38 & $28(16.3)$ & $10(3.5)$ & $\mathrm{df}=6$ \\
\hline $26-30$ & 99 & $28(16.3)$ & $71(25.0)$ & p-value $<0.001$ \\
\hline $31-35$ & 95 & $32(18.6)$ & $63(22.2)$ & \\
\hline $36-40$ & 92 & $31(18.0)$ & $61(21.5)$ & \\
\hline $41-45$ & 75 & $35(20.3)$ & $40(14.1)$ & \\
\hline$\geq 46$ & 49 & $15(8.7)$ & $34(12.0)$ & \\
\hline \multicolumn{5}{|l|}{ Marital status } \\
\hline Married & 317 & $120(69.8)$ & $197(69.4)$ & $X^{2}=13.02$ \\
\hline Divorced & 65 & $22(12.8)$ & $43(15.1)$ & $\mathrm{df}=3$ \\
\hline Single & 47 & $12(7.0)$ & $35(12.3)$ & $\mathrm{p}$-value $=0.005$ \\
\hline Widowed & 27 & $18(10.5)$ & $9(3.2)$ & \\
\hline \multicolumn{5}{|l|}{ Religion } \\
\hline Christian & 367 & $96(55.8)$ & 271(95.4) & $X^{2}=125$ \\
\hline Islam & 78 & $73(42.4)$ & $5(1.8)$ & $\mathrm{df}=2$ \\
\hline Others & 11 & $3(1.7)$ & $8(2.8)$ & p-value $<0.001$ \\
\hline \multicolumn{5}{|l|}{ Education status } \\
\hline No formal education & 30 & $16(9.3)$ & $14(4.9)$ & $X^{2}=90.33$ \\
\hline Quranic & 35 & $34(19.8)$ & $1(0.4)$ & $\mathrm{df}=4$ \\
\hline Primary & 54 & $34(19.8)$ & $20(7.0)$ & p-value $<0.001$ \\
\hline Secondary & 136 & $39(22.7)$ & $97(34.2)$ & \\
\hline Tertiary & 201 & $49(28.5)$ & $152(53.5)$ & \\
\hline \multicolumn{5}{|l|}{ Parity } \\
\hline $1-2$ & 82 & $40(23.3)$ & $42(14.8)$ & $X^{2}=6.166$ \\
\hline $3-4$ & 294 & $100(58.1)$ & $194(68.3)$ & $\mathrm{df}=2$ \\
\hline$\geq 5$ & 80 & $32(18.6)$ & $48(16.9)$ & $\mathrm{p}$-value $=0.046$ \\
\hline
\end{tabular}


In Table. 3, using the enter method, a significant model emerged (F5, $44=$ 372.396, $P<0.0005$, and Adjusted $R$ Square $=0.798$ ). Significant variables are age, educational status, religion, and marital status (Table 3). Educational status has higher impact $($ Beta $=3.114)$ on the patronage of TBAs by respondents. Parity of the respondents do not have a significant impact on their patronage of TBAs $(P=0.548)$.

Table 3: Multivariate analysis of some variables \& patronage of TBA

\begin{tabular}{llll}
\hline Predictor & \multicolumn{4}{l}{ Dependent variable : TBA patronage } \\
\cline { 2 - 4 } Variables & Beta & Exp $(\mathbf{B})$ & P- Value \\
\hline Educational & 3.114 & 22.507 & $<0.001$ \\
Status & 2.486 & 12.018 & $<0.001$ \\
Marital Status & -1.387 & 0.250 & $<0.001$ \\
Age (years) & -2.161 & 0.115 & $<0.001$ \\
Religion & 0.329 & 1.389 & 0.548 \\
Parity & & & \\
\hline
\end{tabular}

\section{Discussion}

In our study, a significant range of services rendered by TBAs were identified by the respondents and $37.7 \%$ of the women utilized TBAs. The finding in our study is comparatively lower than $63.3 \%$ reported in a similar study carried out in southern Nigeria. ${ }^{12}$ With the overall health facility coverage of the LGA standing at 1 per 2,679 population, ${ }^{9}$ one would have expected a $100 \%$ pregnancy and delivery supervision by a skilled health worker. Even though the finding in our study is lower than what was reported for a similar study conducted in the southern part of the country, the patronage of TBAs in our study indicate that the national reproductive health policy that was put in place is yet to achieve its desired effects as it is been hampered by the activities of the TBAs. A more aggressive approach in advocacy and awareness campaign is therefore needed to stem this tide.

In terms of reasons for patronage of TBA by pregnant women, our study identifies cost of care as the main reason. This finding was consistent with that of an earlier study by Onyemocho et $\mathrm{al}^{13}$ but higher than $50.9 \%$ reported from study in Ogun state, Nigeria. ${ }^{14}$ In a similar qualitative study conducted in Sierra Leone, TBAs were valued by mothers, health professionals, and the community because they provide accessible and affordable care to mothers who may otherwise have no access to health services. ${ }^{15}$ Our finding can be attributed to poor governance and insufficient budgetary allocation on health. With Nigeria still having low health expenditure of about $15 \%$ to over 170 million people, additional increment is required to reduce the cost of medical care incurred by patients which will in turn promote optimal utilization of the available health services.
This study also revealed that cultural acceptability and proximity to health facility were some of the reasons women in Benue patronise TBAs. Looking at the World Health Organization requirement of 1 PHC per 10,000 population, the issue of geographical access in our study was not obtainable since the health facility coverage of our study area was 1 per 2,679 population. ${ }^{9}$ However, even if the health facilities were to be within a workable distance, the out of pocket expenses may still limit the respondent's acceptability of the health facilities. Furthermore, the negative attitude of health worker opined by women in our study may account for the findings in our study. Presumptive negative perception of health workers could make the patients build more trust on the services of TBAs who are always available within the community. This may be substantiated with the fact that, TBAs also provide social support to their clients in addition to medical services. ${ }^{6}$ Another important probable reason in our study is the issue of industrial action by health care providers (Figure 2).

In the bivariate and multivariate analysis, women with higher educational qualification patronise TBAs more than the women with lower educational status. This finding implies that significant proportion of women still have good trust in traditional health providers. In the multivariate analysis, a strong association was observed between the educational status, marital status, age or religion and patronage of TBAs; with educational and marital status having more impact as compared to other socio-demographic variables.

This is consistent with a similar studies done in Kenya were the level of education was significantly associated with choice of place of delivery $(\mathrm{P}<0.005) .{ }^{17}$ The minimal influence of husband in the choice of type of health providers demonstrated in our study is against the background of reports that husbands are the main cause of delay in health seeking by women in northern Nigeria. ${ }^{7}$ The result of our study signifies that women with good educational background also stand a chance to benefit good support from their husbands and that will provide opportunities for decision making. By implication, commitment to reduce traditional methods of care and high utilization of orthodox medical care can be achieved through advocacy and behaviour-change communication programmes.

In our study, some of the sociodemographic profiles were inconsistent with the national figures. For instance, considering the study sites being a rural setting, one would have expected the educational 
status to be in line with the national reports where a lot of illiterate individuals are found in the rural areas. However, our study demonstrates the opposite with $44.1 \%$ of the women of reproductive age attaining tertiary institutions of learning.

\section{Conclusion and Recommendations}

A significant proportion of women in Apa LGA of Benue State patronize TBAs for ANC and deliveries despite advocacies for services of skilled birth attendants.

Reasons provided ranges from stability of TBAs services due to repeated industrial action by health workers to proximity and cost of health care. Since majority of the women are educated, financial empowerment of the women through provision of jobs by the Benue State Government and Federal Government should be strengthened to promote the utilization of health facilities that are within the provision of the reproductive policy of the country. The state government should also organise refresher courses and or trainings for the health workers to mitigate the effect of the presumed negative attitude of health workers by women. In the interim, well-designed programmes within permissible standards and trainings of TBAs could be developed as interim measures for effective referrals between TBAs and orthodox health systems in Nigeria thereby reducing preventable causes of maternal mortality. Furthermore, the present study did not look at the opinion of the TBAs and the extent of their competence in the services perceived to be rendered by the respondents, but their patronage as indicated by the respondents in this study serves as a huge missed opportunities to implantation of Maternal and Newborn health intervention if not properly utilized, hence it is also recommended that further research should be carried out on the opinion of the TBAs.

\section{Conflict of interests}

The authors declare no conflict of interests.

\section{Funding}

This work was solely funded by the authors. There was no external fund from any institution or organization.

\section{Acknowledgement}

We are deeply indebted to the respondents who agreed to participate in this study. We thank the spouses of our respondents who are married for allowing the instruments to be administered to their wives. We also acknowledge the support of the resident doctors of the department of Epidemiology and Community Health, Benue state University Teaching Hospital, Makurdi, Nigeria for collecting the data.

\section{References}

1. FMOH, Abuja, Nigeria. National Reproductive Health Policy and Strategy to Achieve Quality Reproductive and Sexual Health for all Nigerians.2001.

2. FMOH, Abuja Nigeria (2011). National Primary Health Care development Agency handbook on essential maternal and newborn care.

3. FMOH, Abuja, Nigeria. National Health Policy: promoting the health of Nigerians to accelerate socio-economic development. 2016.

4. FMOH, Abuja, Nigeria. National Primary Health Care Development Agency, National guidelines for development of primary health care system in Nigeria, $4^{\text {th }}$ Edn. Printed by Damnori Nigeria Ltd. 2016.

5. Akin O. Health care resources in Nigeria: Situation and Prospects, $1^{\text {st }}$ edition, Com-Health Lagos, Nigeria, 2005;1-5.

6. WHO, UNICEF, UNFPA, World Bank Group, and the United Nations Population Division (2016). Trends in Maternal Mortality: 1990 to 2015 (Accessed at data.worldbank.org/indicator/SH.STA.MMRT on $10^{\text {th }}$ january, 2017).

7. Federal Ministry of Health. National Demographic and Health Survey. Abuja: FMOH; 2012.

8. Ogunbosi B, Oladokun R, Awolude O, Brown B , Adeshina O, Kuti M et al. Missed Opportunities for Prevention of Mother-toChild Transmission of HIV (PMTCT) in Ibadan, Southwest Nigeria. World Journal of AIDS;2014; 4: 356-364

9. Benue State Government. Benue Sate Development plan 20162015, BSDP Technical Committee Report of 2016;21-29.

10. Taofeek I. Research methodology and dissertation writing for health and allied health professionals. $1^{\text {st }} \mathrm{Edn}$, Cress Global Link Ltd, Abuja, Nigeria. 2009; 74.

11. National population commission (NPC) [Nigeria] and ICF Macro. National Demographic and Health Survey, Abuja, Nigeria. 2013.

12. Oshonwoh FE, Nwakwuo G, Ekiyor CP. Traditional Birth Attendants and Women's Health Practices: A case study of Patani in Southern Nigeria. J.P public Health Epidemiol.2014; 6(8): 252-61.

13. Onyemocho A,Ishaku BA, Abdujalil AU, Victoria NO, Solomon A. Sociodemographic Correlates of Choice of Health Care Services in Six Rural Communities in North Central Nigeria. Advances in Public Health, Hindawi Publishing Corporation Volume 2014, Article ID 651086, 7 pages http://dx.doi.org/10.1155/2014/651086.

14. Olufunke ME, Akintujoye IA. Perception and utilization of traditional birth attendants by pregnant women attending primary health care clinics in a rural Local Government Area in Ogun State, Nigeria. Int J Women's Health. 2012; 4: 25-34.

15. Florence MD, Dula FP. Practices of Traditional Birth Attendants in Sierra Leone and Perceptions by Mothers and Health Professionals Familiar with Their Care Journal of transcultural Nursing, 2013.

16. Obinna OO, Iheaka PE, Olabisi O, Ezinne PA, Deborah U, Simon DT. Industrial action by healthcare workers in Nigeria in 2013-2015: an inquiry into causes, consequences and control: A cross-sectional descriptive study. Hum Resour Health.2016; 14: 46.

17. Juley-Anne BM. Factors Influencing Delivery Practices among Pregnant Women in Kenya: A case of Wareng District in UasinGishu County, Kenya. International Journal of Innovation and Scientific Research. 2014;10 (1): 50-58. 